\title{
GENERATION OF MOSAIC STEM CELL DERIVED INNER EAR ORGANOIDS TO DETERMINE PARACRINE EFFECTS OF TMPRSS3
}

\author{
Radoslaw Nabrzyski, BS ${ }^{1}$, Pei-Ciao Tang, $\mathrm{PhD}^{2}$, Alpha Alex², Rick F. Nelson, \\ $\mathrm{MD}, \mathrm{PhD}^{2}$ \\ ${ }^{1}$ Indiana Medical Student Program for Research and Scholarship, ${ }^{2}$ Indiana \\ University School of Medicine, Department of Otolaryngology
}

\section{Background and Hypothesis:}

The carefully timed treatment of mouse embryonic stem cell (mESC) cultures with small molecules results in mESC differentiation into 3D organoids containing all components of the inner ear such as hair cells ( $\mathrm{HCs}$ ), support cells and neurons. Loss of TMPRSS3 function, which is a transmembrane extracellular protease, has been previously shown to lead to rapid $\mathrm{HC}$ degeneration between culture days 36 (D36) and D38 in 3D organoids. Mosaic organoids would allow for analysis of developmental dynamics, cell-cell interactions and even therapeutic rescue efficiency. We hypothesized that we could develop an inner ear mosaic organoid containing cells with and without TMPRSS3 and that the Tmprsss $3^{K O}$ mosaic organoids would have greater hair cell survival than Tmprss $3^{K O}$-only organoids due to the compensatory effect of intact TMPRSS 3 on control hair cells within the same vesicle.

\section{Experimental Design or Project Methods:}

Two $\mathrm{mESC}$ cell lines (R1E background) were previously generated using CRISPR-Cas9n. Control reporter line (tdTomato) expresses a tdTomato reporter gene in all cells under the CAG promoter at the ROSA26 locus. Tmprss3 knockout line $\left(T m p r s s 3^{K O}\right)$ contains a 2A-nGFP cassette with a premature stop codon into exon 2 of the Tmprss 3 gene. We generated Tmprss $3^{K O}$ mosaic (Tmprss $3^{K O}$ :tdTomato) and control mosaic (R1E:tdTomato) organoids. The aggregates were analyzed on days 25, 33 and 38 after being fixed, sectioned and stained for tdTomato, SOX2, MYO7A, cleaved CASPASE3, and BK channels using immunohistochemistry.

\section{Results:}

We have successfully used mESCs to generate $\operatorname{Tmprss} 3^{K O}$ mosaic inner ear organoids with similar efficiency to that of control mosaic organoids. Preliminary data suggests that the hair cell survival rates were similar across all vesicle types in the Tmprss $3^{K O}$ mosaic organoids. Additionally, the Tmprss $3^{K O}$ mosaic organoids had a significantly decreased overall BK channel expression by D38.

\section{Conclusion and Potential Impact:}

The successful generation of mosaic organoids achieved here under both conditions sets the stage for future studies of intercellular interactions and therapeutics in this domain. More replicates are necessary to make a definitive conclusion about the effectiveness of control cells on Tmprss $3^{K O}$ rescue. 